\title{
LÍNGUA E CULTURA: A (RE)CONSTRUÇÃO DO SUJEITO À LUZ DO PARADIGMA DA COMPLEXIDADE - UMA REFLEXÃO SOBRE A IDENTIDADE INDÍGENA
}

\author{
Tereza Tayná Coutinho Lopes \\ Marilia de Nazaré de Oliveira Ferreira
}

\begin{abstract}
RESUMO
Embora o Paradigma da Complexidade venha ganhando mais espaço e reconhecimento, até o momento, não se tem conhecimento de estudos que reflitam sob a identidade indígena de suas lentes. Diante disso, este trabalho tem por objetivo apresentar a questáo da identidade como um sistema complexo/caótico imbuído pelo contato de línguas em permanente processo de reconstruçáo.
\end{abstract}

PALAVRAS-CHAVE: Emergência de identidades; Povo parkatêjê; Complexidade.

\section{Introdução}

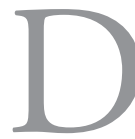

e acordo com Larsen-Freeman e Cameron (2008), podemos entender como sistema complexo um tipo de sistema que abarca um conjunto de componentes heterogêneos que interagem, influenciando uns aos outros. O termo "complexo", nesse contexto, refere-se aos comportamentos emergentes dessas interaçóes. As autoras complementam que, no paradigma da complexidade, a dinamicidade e a mudança são palavras-chave, uma vez que os sistemas complexos evoluem e se adaptam de diversas maneiras, continuamente.

Diante disso, assumimos a identidade social como um sistema complexo, conforme propôs Sade (2009) ao reconhecer o ser humano como um ser social que é construído mediante a interação. 
Este artigo discute a (re)construção identitária indígena, haja vista que os grupos indígenas também estão cada vez mais em interação com outros grupos, sejam indígenas ou não, o que, consequentemente, faz emergir uma variedade de comportamentos complexos, que se entrelaçam com as culturas às quais estão expostos. Um dos objetivos do presente artigo é justamente demonstrar que a identidade do índio, assim como a de todos nós, está em constante processo de reconstruçâo. Para isso, abordaremos aspectos culturais da vida dos integrantes da Comunidade Indígena Parkatêjê.

O entendimento da identidade como um sistema complexo evita a propagação de visóes muitas vezes preconceituosas, pautadas em paradigmas lineares e pré-concebidos. O paradigma da complexidade ${ }^{1}$ nos permite enxergar o ser humano de maneira holística, de forma a podermos compreendê-lo como um todo e não mais de maneira reducionista, considerando somente certos aspectos.

Este artigo está estruturado da seguinte forma: a primeira seção compreende esta introdução; a segunda apresenta conceitos essenciais da complexidade/ caos associados à questáo da identidade; a terceira traz informaçóes sobre a vida dos índios parkatêjê e aborda a forma como tais indígenas demonstram o processo de (re)construção identitária; por fim, apresenta as consideraçóes finais.

\section{A identidade como um sistema complexo}

Esta seção apresenta consideraçóes de caráter teórico acerca dos sistemas adaptativos complexos relacionados à questão da identidade. Para isso, as principais fontes teóricas utilizadas foram Larsen-Freeman (1997), Morin (2002), Larsen-Freeman e Cameron (2008), Resende (2009), Sade (2009) e Martinazzo (2010).

Os sistemas adaptativos complexos, de modo geral, conforme Larsen-Freeman (1997), apresentam as seguintes características: dinamismo, não linearidade, imprevisibilidade, caos, entre outras. As referidas características também estão associadas à chamada Teoria do Caos, a qual se ocupa do estudo de sistemas que se desenvolvem de maneiras totalmente imprevisíveis (LARSEN-FREEMAN; CAMERON, 2008).

1 A denominação 'paradigma da complexidade' relaciona-se à chamada 'ciência novo-paradigma emergente' que surgiu em meados do século XX em oposição ao chamado 'paradigma tradicional da ciência' (VASCONCELLOS, 2002). 
As teorias da Complexidade e do Caos nos fornecem importantes ferramentas para analisar não somente sistemas físicos e biológicos, mas também sistemas sociais, como os identitários, que estão imersos na cultura de um grupo.

Segundo Martinazzo (2010, p. 33), "a identidade humana é um traço característico de cada ser que permite distinguir um indivíduo de outro [...]”. O estudo da identidade como um sistema dinâmico, não-linear, surpreendente e, consequentemente, complexo nos permite, de acordo com Sade (2009), entender o ser humano enquanto ser que é construído mediante a interação com o outro e que se situa em práticas sociais específicas, como a linguagem, que moldam seu comportamento, ao mesmo tempo em que são moldadas por ele.

Sendo a interação uma das palavras-chave para se entender a formação das identidades de cada indivíduo em sociedade, é fundamental termos em mente que é somente por meio do nosso contato com diferentes discursos, culturas, línguas etc., que se dá a construção/reconstrução das identidades de cada pessoa. Nesse sentido, para Martinazzo (2010, p.35) "nossa identidade não é produto genuinamente inato. $\mathrm{Na}$ relação com outros seres humanos e com as outras culturas nós nos tornamos, concomitantemente, semelhantes e distintos. Nos traços de cada homem genérico estão, também, os traços de sua especificidade".

Dessa forma, concebemos a identidade como múltipla e una, pois "compreender o humano é compreender sua unidade na diversidade, sua diversidade na unidade" (MORIN, 2002, p. 55). A identidade social como um sistema complexo exige que enxerguemos as partes que a constituem como um sistema, bem como a forma como elas interagem fazendo emergir situações complexas.

Para Resende (2009), os seres humanos demonstram nas relaçóes com o outro, nos diferentes contextos e de acordo com os diferentes discursos sociais com os quais tenham contato, a emergência de múltiplas identidades que irão contribuir para a formação de um "eu" único e individual. A integração das partes, ou seja, dos diversos "eus" proporciona a constituição desse "todo identitário", que é dinâmico, múltiplo e mutável, segundo a autora.

Acerca da mesma questáo, Sade (2009, p. 216) afirma que "cada encontro social faz com que uma identidade seja emergente, mas essa identidade que emerge possui todas as propriedades das outras, e quando ela emerge, as demais não desaparecem, apenas se mantêm como fundo”. 
Para um melhor entendimento da identidade como um sistema complexo e, consequentemente, fractalizada ${ }^{2}$ é relevante estabelecer sua relação com algumas propriedades propostas por Holland (1995 apud RESENDE, 2009) as quais caracterizam um sistema complexo. Das cinco propriedades apresentadas por Holland, destacamos neste trabalho: agregação, marcação e não-linearidade.

Sobre a propriedade da agregação, Sade (2009) afirma que todos os sistemas são formados por componentes chamados "agregados". Para a autora, a principal diferença entre sistemas simples e sistemas complexos é que nos sistemas complexos os agregados estão em constante interação, gerando comportamentos complexos não-previsíveis, enquanto nos sistemas simples não se verifica a interação entre as partes.

No que diz respeito à questão da identidade, a agregação é constatada na medida em que todos os seres humanos estão no decorrer de suas vidas em constante interação, seja com os outros indivíduos, meio ambiente imediato, instituiçóes sociais etc. E isso possibilita a manifestação da identidade individual. (RESENDE, 2009).

O mecanismo da marcação é, na teoria dos sistemas complexos, um facilitador para a formação de agregados e funciona como um elemento que atrai outros elementos para si, de forma a criar um sistema. Holland (1995 apud RESENDE, p. 42) explica que "as marcaçóes são uma característica universal dos SACs, pois facilitam a interação seletiva. Permite aos agentes escolher entre agentes ou entre objetos que, de outro modo, seriam indistinguíveis”.

Com relação à identidade observamos que a partir das experiências pessoais vividas cada indivíduo será "atraído" para determinados discursos e não para outros. Os discursos, nesse caso, funcionam como marcaçóes nos sistemas complexos, uma vez que nos atraem e contribuem para a formação de agregados ou comunidades de prática (RESENDE, 2009).

As referidas comunidades de prática são comunidades que refletem os interesses em comum de seus membros e o aprendizado coletivo. Como

2 Utilizamos o termo identidades fractalizadas por optarmos pela concepção de Sade (2009), que afirma que tal nomenclatura resgata a noçáo de um todo composto pelas partes do sistema complexo, diferentemente da terminologia identidades fragmentadas, que apesar de ser amplamente utilizada na literatura da área, não contempla a complexidade da questáo da identidade. 
exemplo, podemos citar família, religião, escola, time de futebol, entre outros grupos sociais. Participar de tais comunidades requer dos indivíduos dois componentes: experiência e competência. A competência diz respeito ao conhecimento partilhado das práticas necessárias para o pertencimento grupal, como o uso de uma língua, as rotinas do grupo e o estilo convencionado pelos membros. Já a experiência é mais voltada para o âmbito pessoal e refere-se ao modo como cada indivíduo utilizará seus conhecimentos particulares para contribuir com uma comunidade específica (WENGER 1991, 1998 e 2000 apud RESENDE, 2009).

Dessa forma, a participação em diferentes comunidades de prática faz emergir diferentes identidades, uma vez que a prática social do indivíduo estará condicionada pelos discursos específicos de cada comunidade. Resende (2009) sublinha que quanto mais um indivíduo se rende a vários discursos, maior será a multiplicidade de seus "eus" emergentes.

Ao se referir à propriedade da não-linearidade, Sade (2009) explica que se trata de uma das características mais marcantes dos sistemas complexos a qual também pode ser observada em questóes identitárias. Dessa forma, todos os indivíduos são socialmente construídos a partir das práticas sociais que vivenciam, no entanto, nenhum destes sujeitos será exatamente igual à soma dos discursos com os quais tenham contato. Mas, da interação entre determinado indivíduo e seu meio, situaçóes imprevisíveis podem acontecer, uma vez que "nenhum indivíduo é exatamente igual à soma dos discursos das instituiçôes as quais frequentou" (SADE, 2009, p. 2008).

Enxergar a identidade como um sistema complexo faria com que fossem menos frequentes situaçóes preconceituosas embasadas em visôes lineares da identidade de cada qual. A perspectiva linear da identidade gera rótulos e "é uma atitude equivocada que reflete o total desconhecimento da natureza complexa do ser humano" (SADE, 2009, p. 209).

Com relação à Teoria do Caos, verificamos que a referida teoria nos oferece conceitos pertinentes para a caracterização da identidade como um sistema caótico, como por exemplo, as noções de atratores, pontos de bifurcação e fractais.

Segundo Sade (2009), o atrator é um padrão de movimento que se repete de maneira constante. Stewart (1991 apud SADE 2009, p. 211) explica que "a essência de um atrator é uma porção do espaço de fase tal que qualquer 
ponto que se ponha em movimento nas suas proximidades se aproxima cada vez mais dele”. Assim, qualquer ponto próximo ao atrator é atraído para o seu padrão de movimento.

Em relação à identidade, Sade (2009) informa que o conceito de atratores pode ser associado ao conceito de forças centrípetas investigado por Bakhtin, no qual esta seria a força que concorre para a unificação na formação de um sistema. A autora comenta que o comportamento linguístico de determinado grupo social surge e é desenvolvido a partir de forças históricas que influenciam na evolução desse grupo. Dessa forma, a língua deve ser entendida como uma entidade saturada de ideologias que atua na sociedade como uma força centrípeta que trabalha para a unificação e centralização verbo-ideológica, sociopolítica e cultural.

Ainda acerca do mesmo assunto, cabe sublinhar que os indivíduos incorporam ideologias de determinada língua a partir de suas vivências em rotinas sociais. Tais rotinas nada mais são que um padrão de comportamento que se repete, continuamente, ou seja, um atrator. Todavia, os atratores não devem ser entendidos apenas como um padrão de comportamento que se repete, mas também como padróes em constante mudança. A esse atrator dar-se o nome de atratores estranhos e ele é algo típico dos sistemas caóticos (RESENDE, 2009).

A identidade, tal como os atratores estranhos, está sempre a mudar, dinamicamente. Sade (2009, p. 212) afirma que "a identidade é configurada e reconfigurada de acordo com o ambiente social". Ou seja, os diversos discursos com os quais entramos em contato contribuem para o processo contínuo de transformação identitária.

Semelhantemente acontece com relação à noção de pontos de bifurcação dos sistemas caóticos, que são pontos que podem causar uma mudança na trajetória de uma atrator. Ou seja, quanto mais cedermos a diferentes discursos, mais nos depararemos com bifurcaçóes ou pontos de decisóes que geram identidades emergentes. (RESENDE, 2009)

Com relação ao conceito de fractais, Sade (2009, p. 215) afirma que "o fractal é a representação geométrica do Caos”. Ele apresenta como propriedades a autossemelhança e as infinitas possibilidades de subdivisóes. O sistema identitário, bem como um fractal, não é fixo e estável, pelo contrário, se bifurca e se ramifica a cada encontro social. Isso possibilita entendermos o processo de emergência identitária como infinito. 
Diante do embasamento teórico apresentado, passaremos a discutir, na próxima seção, a questão da identidade indígena à luz da complexidade/caos, com enfoque aos parkatêjê.

\section{O caso dos índios parkatêjê}

Nesta seção, teceremos com base principalmente em Araújo (1989), Ferreira (2003), Jópaipare (2011) e Ferraz (1984), algumas consideraçóes, sobre o percurso histórico e a situação atual da comunidade parkatêjê, a fim de evidenciar a questão da reconstrução de seu sistema identitário. Para tanto, concebemos o sistema identitário como um sistema complexo e caótico.

O povo parkatêjề $\hat{e}^{3}$ também é conhecido na literatura especializada como "Gavião do Pará" - habita, atualmente, uma reserva indígena chamada Mãe Maria (RIMM), situada no município de Bom Jesus do Tocantins, sudeste do estado do Pará.

\section{Percurso histórico: identidades emergentes}

Para uma melhor compreensão acerca da situação sociolinguística da referida comunidade, é necessário dar a conhecer as diversas fases vivenciadas por seus integrantes.

No passado, o povo parkatêjê enfrentou um difícil período de sobrevivência na floresta, em consequência de lutas internas e de várias epidemias que quase resultaram em sua extinção. Nessa fase de sua trajetória, eles se depararam com um ponto de bifurcaçáo decisivo, pois recorrer ou não à sociedade nacional definiria a sua sobrevivência ou o seu desaparecimento como um grupo. De acordo com Ferreira (2003), decidir pela aproximação definitiva com a 'civilização' foi a chance de sobrevivência dos índios parkatêjê. A partir de então, iniciou-se o primeiro momento de intenso contato desse povo com a sociedade envolvente.

Os parkatêjê também se uniram a outros três grupos indígenas: os Akrãtikatêjê, os Kyikatêjê e os Róhôkatejê, justamente com o objetivo de garantir tanto sua sobrevivência física, quanto cultural. Essa decisão pode ser

3 Segundo dados do posto de saúde da comunidade, a aldeia parkatêjê é formada, atualmente por cerca de 478 pessoas. 
vista como outro ponto de bifurcação decisivo para a continuação desse povo, tendo em vista a situação de ameaça em que se encontrava. Naquela época, o jovem líder Krôhôkrenhum, que ainda hoje permanece como chefe dos parkatêjê, foi o principal intermediador da união entre os referidos grupos. Juntos, em uma mesma comunidade, partilham de costumes, festas e até mesmo as línguas bastante semelhantes.

Tanto a união dos parkatêjê com os outros grupos indígenas, quanto sua aproximação com os não índios, contribuiu para a formação de agregados. Essa agregação deu condições de sobrevivência ao povo parkatêjê. Em outras palavras, a partir da forma como se agregaram e da complexidade emergente da interação entre seus integrandes foi garantida a vida e o fortalecimento da comunidade como um todo. As palavras do chefe Krôhôkrenhum corroboram esse acontecimento: "Então nós misturamos. Hoje nós estamos seguros que nem capim, nós estamos fortes que nem capim. [...]. Nós não estamos puros, mas nós aumentamos de novo [...]" (JÓPAIPARE, 2011, p. 94).

As novas relaçóes estabelecidas entre os parkatêjê e a sociedade envolvente, culminaram em identidades emergentes. Um exemplo disso é descrito por Ferraz (1984) ao mencionar as mudanças percebidas no que diz respeito ao envolvimento desses índios com as questóes econômicas dos não índios. A autora afirma que a organização do grupo, que era, tradicionalmente, pautada na reciprocidade, passou a se basear no sistema de troca monetária. Eles também aprenderam o sentido de propriedade particular e começaram a fazer distinçôes entre classes como "ricos" e "pobres".

Conforme Ferreira (2003), em meados de 1970 o povo parkatêjê conseguiu dar início a um novo momento de sua história. Reestabelecidos e com as experiências adquiridas, passaram a assumir o controle definitivo sobre a economia dos produtos de seu território e a protagonizar suas decisóes. Deu-se, assim um novo movimento entre eles no sentido de reavivarem sua cultura e tradiçóes que pareciam esquecidas diante de tantas dificuldades e novas influências.

A aldeia dos parkatêjê também é chamada por alguns de seus integrantes, Kupejipôkti, cujo significado é terra "rodeada pelos não índios", tal denominação evidencia a proximidade da aldeia em relação aos municípios circundantes. Esse fato somado ao intenso acesso aos discursos e as tecnologias não indígenas passaram a contribuir para que, infelizmente, muito da cultura, dos 
conhecimentos tradicionais e até mesmo da língua indígena fosse deixada à sombra da cultura dominante.

Diante disso, Ferraz (1984) destaca algumas estratégias de Krôhôkrenhum para tentar reverter a preocupante situação, entre as quais, o seu esforço para agregar, na aldeia, índios que estivessem dispersos nas cidades ou em outras aldeias. De acordo com Araújo (1977), o líder tradicional também voltou a incentivar a realização de festas tradicionais, cerimônias, narração de histórias no pátio, além de outras atividades culturais.

Em linhas gerais, podemos dizer que esse novo momento vivenciado pelo povo parkatêjê deu início a um movimento de resgate de sua cultura que permanece sendo praticado até os dias atuais. No entanto, como explanaremos na próxima subseção, eles ainda continuam um trabalho de reafirmação de suas origens, ao mesmo tempo em que buscam somar novos conhecimentos vindos "de fora" da aldeia.

\section{Povo parkatêjê: uno e múltiplo}

Conforme citado, a comunidade indígena parkatêjê se esforça para fortalecer seu patrimônio cultural e linguístico, assim como para agregar saberes da sociedade envolvente. Muitos de seus integrantes buscam, por exemplo, melhores condiçóes intelectuais e profissionais, a fim de garantir seus direitos e assegurar melhorias para a comunidade.

A tecnologia é uma ferramenta que já faz parte do universo da comunidade e serve também de aliada para a documentação e o resgaste da cultura parkatêjê. Decerto, configura-se como uma grande necessidade para a inclusão dos indígenas nos mais variados espaços sociais, entre os quais, a Universidade. Nesse sentido, em 2011, foi implantado na comunidade parkatêjê o projeto Inclusão digital para estudantes Indigenas da comunidade parkatêjêe. Esse empreendimento foi coordenado pela Dra ${ }^{a}$. Marília Ferreira, docente da Universidade Federal do Pará, e teve como objetivo propiciar a inclusão digital aos estudantes indígenas da comunidade e, assim, inseri-los na era da informação.

A escola indígena da aldeia chamada Escola Pèmptykre Parkatêjê, também funciona de modo a tentar englobar a diversidade linguística/cultural do povo e as demais disciplinas comuns na educação escolar de modo geral. 
Conforme Silva (2014), no ano de 2013, os parkatêjês assumiram a administração da escola e somam-se ao quadro de professores índios e não índios.

A busca dos indígenas por melhoria de vida, espaço e respeito na sociedade ainda esbarra muitas vezes em atitudes preconceituosas pautadas em visões lineares que negam a diversidade e dinamicidade do sistema identitário. Muitos não índios ainda insistem em negar ao indígena sua inclusão em diversos segmentos da sociedade nacional tendo como argumento uma visão "mítica" do indígena. De acordo com Sade (2009) esse tipo de atitude orientada por rótulos é equivocada e reflete o total desconhecimento da complexidade inerente ao ser humano.

O povo parkatêjê tenta hoje desconstruir a errônea ideia de uma identidade única. Os indígenas que compóem a comunidade demonstram novas ideias, novas ações, buscam adquirir novos conhecimentos, sem, no entanto, excluir os saberes tradicionais que fazem parte de sua trajetória. O desafio é justamente demonstrar, como concebe Morin (2002), a unidade e a multiplicidade que faz parte da questão identitária de um povo ou indivíduo.

\section{Considerações finais}

A discussão apresentada no artigo em tela refletiu a identidade indígena como um sistema complexo. Em outras palavras, o sistema identitário parkatêjê foi concebido nessas páginas como algo dinâmico, não-linear e em constante transformação. Aspectos da história e do modo de vida desse povo serviram de base para a análise acerca da identidade indígena, entendendo-a em constante (re)construção, uma vez que com a interação tanto com os não índios, quanto com indígenas de outras etnias emergiram comportamentos que refletem o povo parkatêjê, atualmente.

$\mathrm{O}$ artigo ressaltou que a comunidade parkatêjê se empenha para fortalecer seu patrimônio linguístico e cultural, sem, no entanto, ignorar os conhecimentos oriundos da sociedade envolvente. Dessa forma, buscam melhores condiçóes de vida para a comunidade, agregam conhecimentos e revelam múltiplas identidades. Em nosso ponto de vista, o reconhecimento das múltiplas identidades do indígena ajuda a desconstruir a propagação de visóes preconceituosas e lineares, baseadas em estereótipos.

Cabe acrescentar que, neste artigo, o paradigma da complexidade ofereceu a possibilidade de uma perspectiva de análise que contempla a situa- 
ção sociocultural tanto da comunidade parkatêjê, quanto de diversas outras comunidades indígenas. Isso porque muitos povos indígenas têm se esforçado, atualmente, para agregar saberes tradicionais e conhecimentos da cultura dominante. Sendo assim, concluímos com as palavras de Left (2003 apud AMAZONENSE, 2012) as quais, a nosso ver, reforçam esse modo de pensar:

no jogo democrático e no espaço da complexidade, a identidade não é somente a reafirmação do uno na tolerância aos demais; é a reconstituição do ser pela introjeção da outridade - a alteridade, a diferença, a diversidade -, na hibridação da natureza e da cultura, através de um diálogo de saberes (LEFT, 2003 apud AMAZONENSE, 2012, p. 49).

\section{Referências}

AMAZONENSE, Terezinha. "Conhecimento dos povos indígenas e a teoria da complexidade: educação ambiental e a valorização do patrimônio dos povos indígenas”. Revista Geonorte. v. 3 (n. 4). p. 71-83, Amazonas, 2012.

ARAÚJO, Leopoldina. Semântica gerativa da lingua gavião-jê. 1977. Dissertação (Mestrado) - Universidade Federal de Santa Catarina, Florianópolis, 1977.

. Aspectos da língua gavião-jê. 1989. Tese (Doutorado) - Universidade Federal do Rio de Janeiro, Rio de janeiro, 1989.

FERRAZ, Iara. Os Parkatêjê das matas do Tocantins: a epopeia de um líder Timbira. 1984. Dissertação (Mestrado) - Universidade de São Paulo, São Paulo, 1984.

FERREIRA, Marília de Nazaré O. Estudo morfossintático da língua parkatêjê. 2003. Tese (Doutorado) - Universidade Estadual de Campinas, São Paulo, 2003.

JÓPAIPARE, Toprãmre Krôhôkrenhūm. Me ikwỳ tekjê ri: isto pertence ao meu povo. 1. ed. Marabá, PA: Gknoronha, 2011.

LARSEN-FREEMAN, Diane. "Chaos/complexity science and second language acquisition”. Applied Linguistics, v 18, n. 2. p. 141-65, 1997.

LARSEN-FREEMAN, Diane; CAMERON, Lynne. Complex Systems and Applied Linguistics. Oxford: Oxford, 2008. 
MARTINAZZO, Celso José. "Identidade Humana: unidade e diversidade enquanto desafios para uma educação planetária”. Contexto \& Educação, ano 25, n. 84, jul./dez., p. 31-50, Rio Grande do Sul, 2010.

MORIN, Edgar. Os sete saberes necessários à educação do futuro. Tradução de Catarina Eleonora F. da Silva e Jeanne Sawaya. 2. ed. São: Cortez; Brasília: UNESCO, 2002.

RESENDE, Liliane Assis Sade. Identidade e Aprendizagem de inglês sob a ótica do caos e dos sistemas complexidade. 2009. Tese (Doutorado) - Universidade Federal de Minas Gerais, Belo Horizonte, 2009.

SADE, Liliane Assis. Identidade e aprendizagem de inglês pela ótica da complexidade. In: PAIVA, Vera Lúcia Menezes de Oliveira e; NASCIMENTO, Milton do (Org.). Sistemas adaptativos complexos: lingua(gem) e aprendizagem. Belo Horizonte: Faculdade de Letras da UFMG, 2009, p. 205-226.

SILVA, Maria de Nazaré Moraes da. A tradição oral no ensino de línguas indígenas: uma proposta para o povo parkatêjề. 2014. Dissertação (Mestrado) - Universidade Federal do Pará, Pará, 2014.

VASCONCELLOS, Maria José Esteves de. Pensamento Sistêmico: O novo paradigma da ciência. Campinas, SP: Papirus, 2002.

\section{LANGUAGE AND CULTURE: THE RECONSTRUCTION OF THE INDIVIDUAL TO COMPLEXITY PARADIGM - REFLECTION ABOUT INDIGENOUS IDENTITY}

ABSTRACT: Although the Paradigm of Complexity has gained more space and recognition, until the present moment, it does not know studies that specifically reflect indigenous identity. So, this work aims to present the question of identity as a complex/chaotic plain of language contact in permanent reconstruction process.

KEYWORDS: Emergency identities; Parkatêjê; Complexity.

Recebido em: 03/02/2016 Aprovado em: 09/08/2016 